\title{
Regulatory effects of laminin derived peptide on microtissue formation for tissue engineered scaffold-free constructs
}

\author{
Ziyşan Buse Yaralı Çevik ${ }^{1}$, Ayşe Ördek²๑, Ozan Karaman ${ }^{1,2} \odot$ \\ ${ }^{1}$ Biomedical, Test Calibration Application and Research Center, İmir Katip Çelebi University, İzmir, Turkey; ${ }^{2}$ Department of Biomedical \\ Engineering, Faculty of Engineering and Architecture, İzmir Katip Çelebi University, İzmir, Turkey
}

\begin{abstract}
Objectives: Vascularization is an important stage for tissues and organs. The vascular network is succeeded by the attachment, spreading, proliferation of endothelial cells, and the completion of endothelialization. Endothelization can be mediated by laminin-derived peptides on microtissues. It is known that laminin-derived Tyr-Ile-Gly-Ser-Arg (YIGSR) peptide contributes to endothelial microtissue formation by promoting increased adhesion and proliferation of endothelial cells. This study aims to determine the efficacy of the laminin-derived YIGSR peptide in Human Umbilicial Vein Endothelial Cell (HUVEC) scaffold free microtissues (SFMs).

Methods: After solid phase synthesis of YIGSR, microtissues were formed as SFMs. SFMs were cultured with $0 \mathrm{mM}$ (control group), $1.5 \mathrm{mM}$ and $3 \mathrm{mM}$ YIGSR peptide. Diameters and viability analysis of HUVEC SFMs were performed on the $1^{\text {st }}, 4^{\text {th }}$ and $7^{\text {th }}$ days.

Results: The diameters of control SFMs group decreased day by day. Diameters of 3 mM YIGSR SFMs increased on the $1^{\text {st }}$ and $4^{\text {th }}$ days but significantly decreased on the $7^{\text {th }}$ day. On the other hand, $1.5 \mathrm{mM}$ YIGSR had a tendency on tissue formation because of increased diameter. As a result of the viability, YIGSR peptide increased cell viability.

Conclusions: It has been determined that $1.5 \mathrm{mM}$ YIGSR is the optimum amount for enlargement and viability of HUVEC SFMs. The concentration has contributed to proliferation and viability of endothelial SFMs. Thus, $1.5 \mathrm{mM}$ YIGSR has been found as the most promising peptide concentration for increasing vascularization.

Keywords: Scaffold free microtissues, HUVEC microtissue formation, YIGSR peptide synthesis
\end{abstract}

$\mathrm{T}$ issue engineering studies have become popular in the scientific world with the increasing need for organ transplantation. One of the difficulties of organ transplantation is that the tissue cannot be vascularized $[1,2]$. However, vascularization is essential for tissue viability. Nutrient and oxygen deficiency causes loss of functions of organs or tissues and necrosis. However, the formation of a stable microvascular network is required for long-term viability and cellular function $[3,4]$. To secure tissue functions, the vascularization period should be understood clearly.

Vascularization is a process that plays a key role for viability of tissues. It is known that the signal network that endothelial cells establish with the extracellular matrix $(\mathrm{ECM})$ is the beginning of new vessel formation. Endothelial cells are flat epithelial cells 
covering the inner surface of the vessel, located between blood and vein walls. Human Umbilical Vein Endothelial Cells (HUVECs) are the most commonly used cell types in vascular research. HUVECs have high proliferation capacity during vascularization [3]. The formation of vasculogenesis mainly begins with the proliferation of endothelial cells and continues with the migration of cells to the vascular formation region. Eventually forms a tubular structure in response to vascular growth factors $[5,6]$. Therefore, the proliferation and viability of HUVECs are critically important to understand the vascular mechanisms.

Although preliminary experiments of tissue engineered studies are mostly conducted in two dimensional (2D) cell culture [7, 8], fundamental behaviours and functional properties of cells are restricted by $2 \mathrm{D}$ culture. Traditional 2D culture is also limited for extracellular matrix (ECM) production [9]. The lack of ECM affects proliferation, cell survival mechanism, differentiation of cells and mechano responses. Moreover, the limitations of the 2D monolayer system engenders non-transferable nutrients, oxygen, and waste. The limitation causes to break down cell metabolism [10]. However, Baker and Chen [11] showed that 3D culture improved the physiological structures and functional properties of the cells. One of the types of 3D is scaffold free microtissues (SFMs). SFMs can be regarded as an ideal model because they have similarities to the in vivo cells in terms of expression of genes and production of proteins $[12,13]$. Since ECM is one of the main factors that play a role in the vascularization process, limited production of ECM may cause the process to be poorly understood. Therefore, considering architecture and cell to matrix interaction of vessels, SFMs may be more realistic approaches than traditional 2D methods. SFMs can mimic natural tissue responses and productions of ECM proteins. It allows intercellular interactions and synthesizes their own ECM [13].

Proteins, one of the basic components of living things, have various mechanisms of action in endothelial cells. Proteins consist of different bioactive sequences. Specific chains allow for easier observation of the effects of the protein. Proteins or protein fragments which are located in the basal membrane are known to play an important role in cellular behavior. Laminin, consisting of three polypeptide chains, is one of the main glycoproteins of the basal lamina. It has the effects of increasing the lifespan and quality of endothelial cells $[3,14]$. The glycoprotein affects

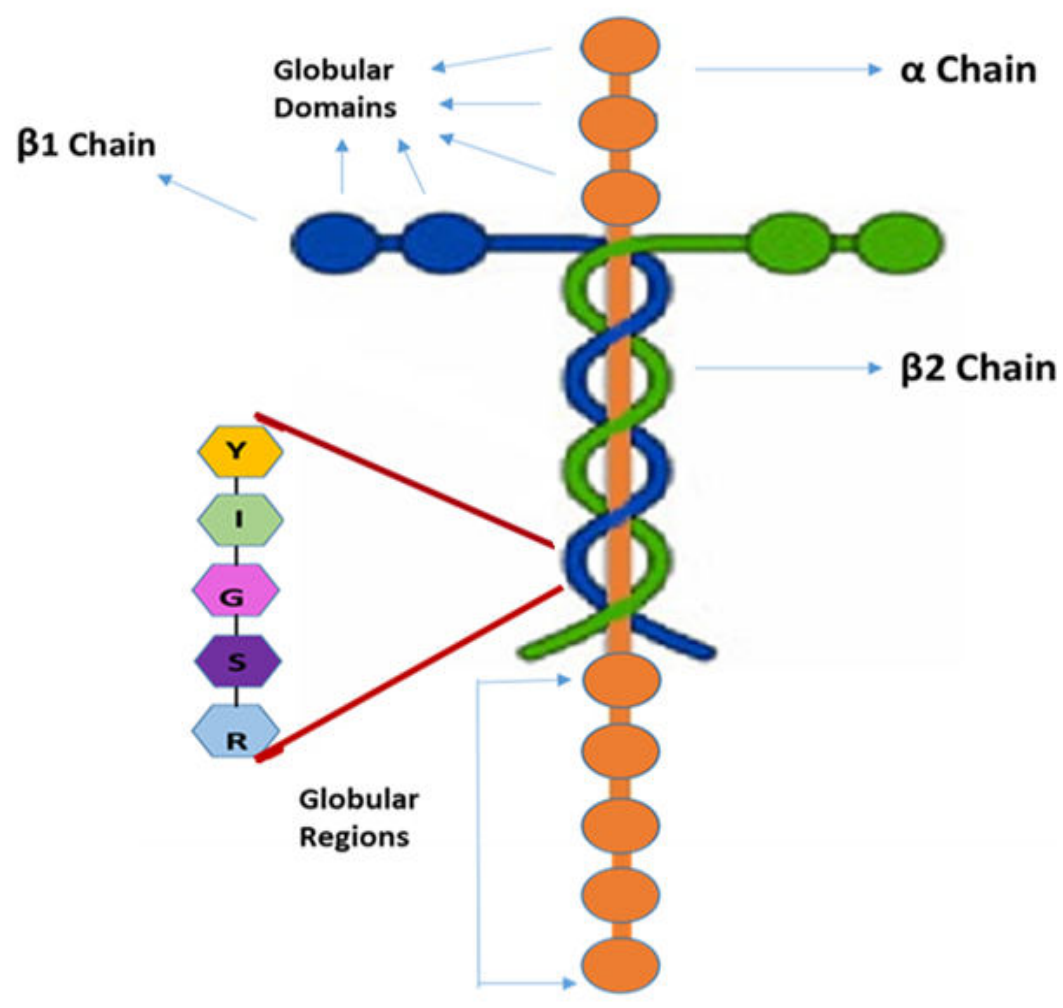

Fig. 1. YIGSR sequence configuration on laminin structure. 
growth, differentiation, adhesion, proliferation and spreading of cells $[15,16]$. Tyr-Ile-Gly-Ser-Arg (YIGSR) sequence is one of the active parts of the laminin protein. The part is found in the $\beta 1$ chain of the laminin (Fig. 1) [17]. Previous studies have been shown that YIGSR has effects on various cellular events such as differentiation, migration and proliferation [18-21]. The peptide has also the ability of spreading and growth-promoting effects of endothelial cells $[3,22,23]$. Identification of concentration of YIGSR sequence is important in the activity of endothelial cells. Previous studies have shown that the growth, adhesion and migration of endothelial cells depend on YIGSR concentrations [3, 22, 24, 25]. YIGSR leads to proliferation and endothelialization of HUVECs in the monolayer system. In light of this information, laminin-derived YIGSR peptide can be used as a regulator for the micro-vascularization in tissue-engineered constructs. However, the effects of YIGSR on the fabrication of HUVECs SFMs has not been determined in the literature yet.

The study aims to determine the optimum lamininderived YIGSR peptide amount on scaffold-free HUVEC microtissue. The viability and proliferation level of endothelial cells are important for prevascularization. Martin, F. et al showed that the differentiation state and development of the generated SFMs can be identified by diameter calculation and SFMs maturation [26]. Moreover, Karaman and Yarali [27] demonstrated that SFMs diameter measurement can relate to SFMs growth and viability analysis. Therefore, diameter analysis can be used to identify healthy growing SFMs [27, 28]. In this context, the diameter and viability analyzes have been performed on HUVEC SFMs with different YIGSR peptide concentrations.

\section{METHODS}

\section{Synthesis of YIGSR Peptide}

All chemicals used for peptide synthesis were purchased from AAPPTEC (Louisville, KY, USA). TyrIle-Gly-Ser-Arg (YIGSR) sequences were added on 9 fluorenyl methoxycarbonyl (Fmoc) protected 4Methylbenzhydrylamine (MBHA) resin $(0.67 \mathrm{mmol} / \mathrm{g}$ loading capacity) as previously described procedure [28]. Briefly, the resin was swollen by dimethylfor- mamide (DMF) for 30 minutes. Then, deprotection process was performed to separate the Fmoc from resins. Under the nitrogen gas, 2 eq. (based on loading capacity of resin) Fmoc-protected amino acid, 2 eq. 1 Hydroxy benzotriazole (HOBt), 2 eq. O-Benzotriazol1-yl-N,N,N,N' tetrametiluronyum-hexafluorophosphate (HBTU) and 4 eq. N,N Diisopropylethylamine (DIEA) was added in DMF. This mixture was incubated for 4 hours to bind amino acids. After determining whether the amino acid was bound with the ninhydrin test, Fmoc protecting group ends were removed by using cyclohexylamine. To complete the process, the amino acids of YIGSR were added sequentially. After peptide synthesis was carried out, the obtained sequence was cleaved from resin by using $2.5 \%$ triisopropylsilane (TIPS), $2.5 \%$ distilled water (DIW), and 95\% trifluoroacetic acid (TFA). This mixture was shaken gently 1 hour per $20 \mathrm{~min}$. Then, ice cold $\left(-20^{\circ} \mathrm{C}\right)$ diethyl ether was added. After the suspension was centrifuged at $4500 \mathrm{rpm}$ and $25^{\circ} \mathrm{C}$ for 10 minutes. Finally, the obtained pellet was freeze-dried for 5 hours.

\section{Culture of Human Umbilical Vein Endothelial Cells (HUVECs) SFMs}

All cell culture equipment and reagent were taken from Sigma (St. Louis, Missouri, ABD) and HUVECs were taken from Ege University Bioengineering Department. HUVECs were cultured at $36^{\circ} \mathrm{C}, 5 \%$ carbon dioxide, 70-80\% humidity. Dulbecco's Modified Eagle Medium (DMEM) which contains 10\% Fetal Bovine Serum (FBS), 1\% L-Glutamine, 1\% Penicillin/Streptomycin was used to culture HUVECs. The medium was refreshed per 2 days. After reach to $80-90 \%$ confluency, cells were washed with Phosphate Buffer Saline (PBS). After trypsinization with Trypsin/EDTA, $60.000 / 75 \mu \mathrm{l}$ cells added into 3D agarose mold.

Agarose mold which is prepared as 2\% agarose was constructed by sterilized 3D Petri Dish. Agarose mold was incubated in Endothelial Basal Medium (EBM-2, CC3156, Lonza) media without serum. After removing media from agarose, the molds were incubated for 30 minutes to allow the cells to settle into the wells. Subsequently, EBM-2 was added on agarose mold.

$1.5 \mathrm{mM}$ YIGSR and $3 \mathrm{mM}$ YIGSR peptide concentrations were prepared with EBM-2 as serum free (Fig. 2). Then the mixtures were filtered by $0.22 \mu \mathrm{m}$ 


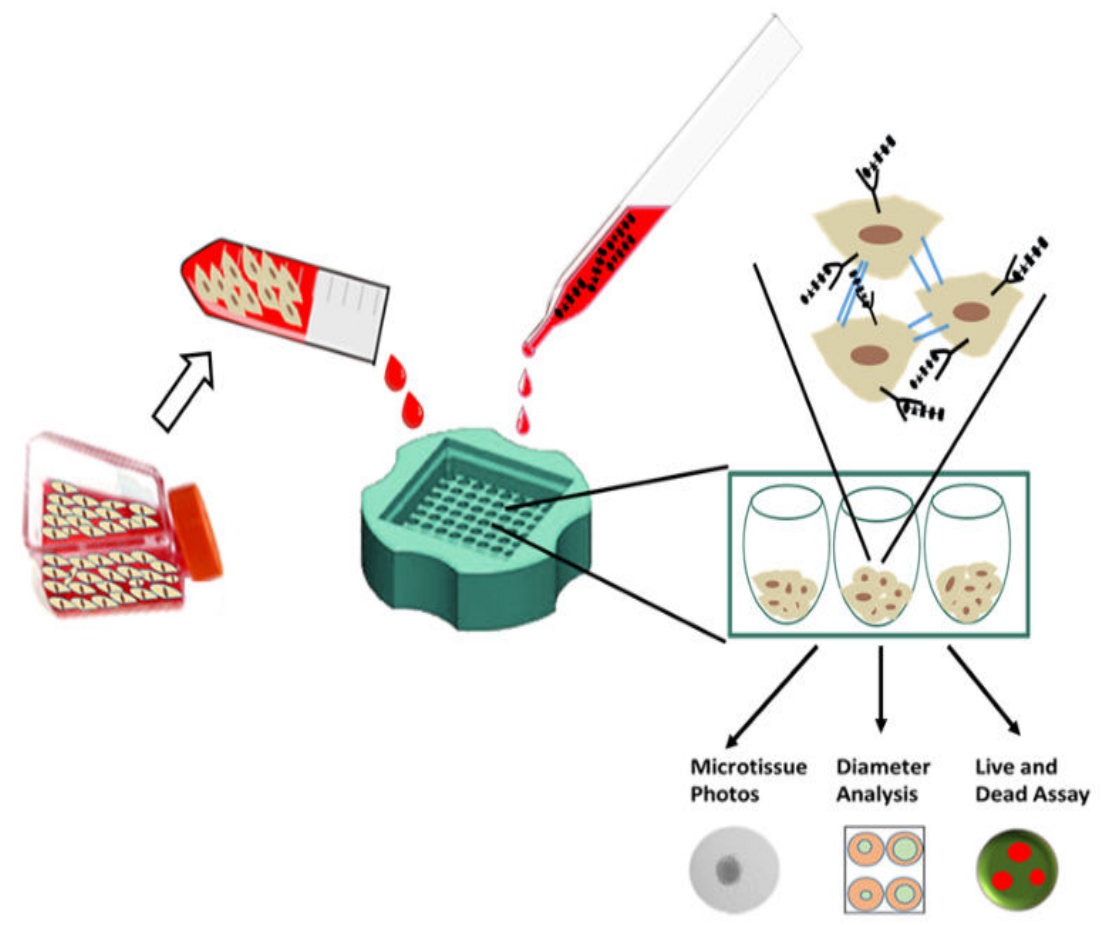

Fig. 2. Diagram of microtissue fabrication and application of YIGSR peptide on HUVEC SFMs: After monolayer culture of HUVEC, SFMs were fabricated in 3D Petri Dish. Control, $1.5 \mathrm{mM}$ and $3 \mathrm{mM}$ YIGSR concentrations were analyzed by images, diameter and viability analysis of SFMs.

microfilter. Only EBM-2 were used without YIGSR concentration as a control group. Each experimental group was performed as triplet treatments $(n=3)$.

\section{Diameter Analysis of HUVEC SFMs}

To calculate and analyze enlargements of microtissue, diameter analysis was performed. Microscopic images of the microtissues were taken on the 1st, 4th and 7th days by using Cell Sense Entry software (Olympus, Germany). Diameter lengths of different YIGSR containing microtissues in each group were measured by Image-J (National Institutes of Health, Bethesda, MD, USA) software. Average lengths and standard errors were calculated as presented in Fig. 3.

\section{Viability effects of YIGSR peptides on HUVECs SFMs}

To understand the effects of different YIGSR concentrations to the viability of HUVEC SFMs, viability assay was performed. The protocol was applied as described in previous studies $[27,28]$. The rate of live or dead cells in microtissue was indicated by Double Staining Kit (Dojindo, Molecular Technologies, Inc, Japan). After media was removed, the agarose molds were washed 5 times with PBS. Images of live and dead cells were taken by Olympus fluorescent microscope. Images were taken 3 times for each SFMs ( $\mathrm{n}=$ 9). Each live and dead cell images were merged. Additionally, fluorescence pixel intensities for each microtissue group were measured by Image-J software.

\section{Statistical Analysis}

All experimental data was subjected to a one-way analysis of variance (ANOVA) with Tukey's post hoc test at a significance level of $p^{*}<0.05, p^{* *}<0.01$ and $p^{* * *}<0.001$.

\section{RESULTS}

HUVEC SFMs with concentrations of $0 \mathrm{mM}, 1.5 \mathrm{mM}$ and $3 \mathrm{mM}$ YIGSR were cultured as shown in Fig. 2. 0 $\mathrm{mM}$ YIGSR peptide concentration was used as negative control. Images of SFMs were taken on the $1^{\text {st }}, 4^{\text {th }}$ and $7^{\text {th }}$ days as shown in Fig. 3. Three images of three microtissues from each plate were taken $(n=9)$ by using an inverted microscope. As it is seen, all microtissue formations were greatly accomplished on the 


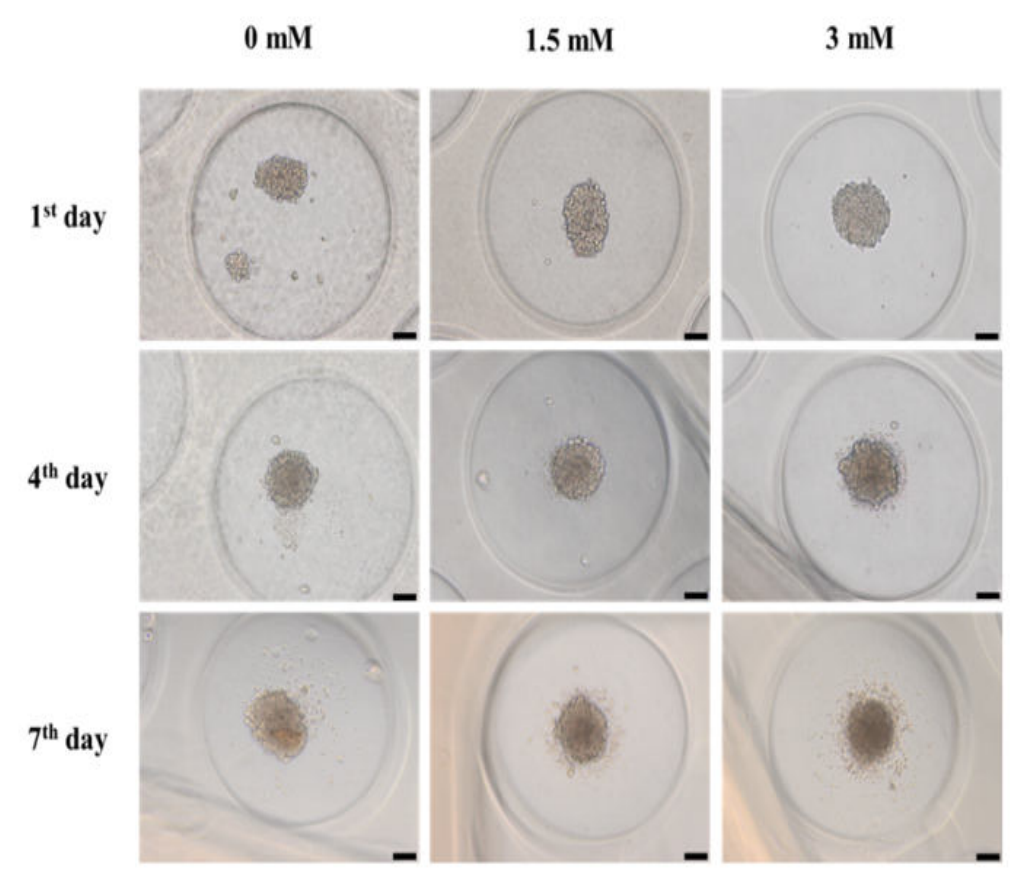

Fig. 3. Micrographs of SFMs at different concentrations on 1st, 4th and 7th days. Scale bar represents $100 \mu \mathrm{m}$ size.

first day. In the following days, microtissue formation first day are $219.89 \pm 4.07 \mu \mathrm{m}, 252.2 \pm 10.2 \mu \mathrm{m}, 291.5$ continued successfully. $\pm 8.9 \mu \mathrm{m}$, respectively. On the fourth day, average diThe diameters of the microtissues were measured with $\quad$ ameters are $217.35 \pm 4.15 \mu \mathrm{m}, 264.8 \pm 3.6 \mu \mathrm{m}, 284.5$ Image-J Software (NIH) for each experimental group. $\pm 2.65 \mu \mathrm{m}$, respectively. At the end of the experiments, The average diameters of microtissues in $0 \mathrm{mM}, 1.5$ diameter measurements are $206.38 \pm 5.8 \mu \mathrm{m}, 288.66$ $\mathrm{mM}$ and $3 \mathrm{mM}$ YIGSR peptide concentrations on the $\pm 6.9 \mu \mathrm{m}, 280.14 \pm 3.14 \mu \mathrm{m}$, respectively.

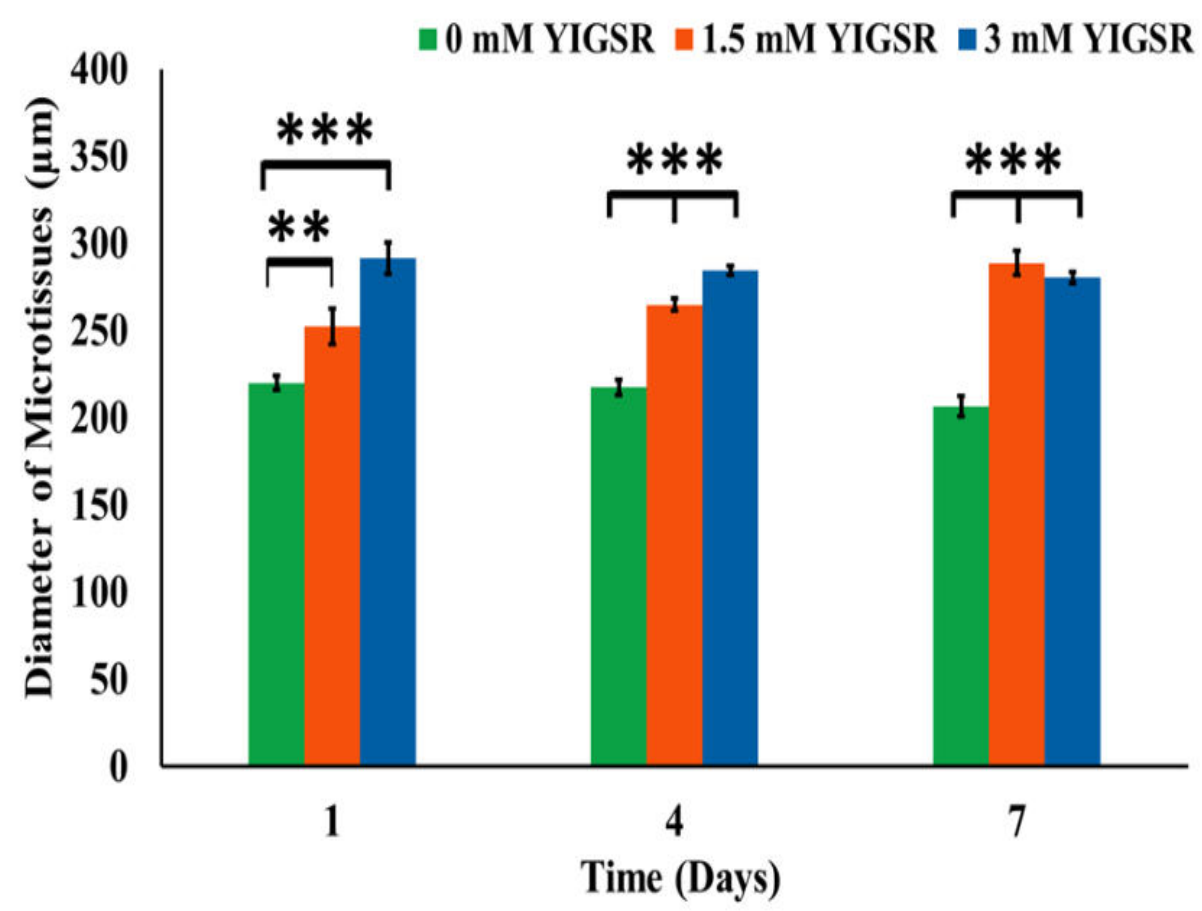

Fig. 4. Effects of $1.5 \mathrm{mM}$ and $3 \mathrm{mM}$ YIGSR concentration on HUVEC microtissue diameters. 
On the 1st, 4th and 7th days, the highest significant differences were observed at $0 \mathrm{mM}$ and $3 \mathrm{mM}$ YIGSR concentrations $(* * * p<0.001)$. It is also seen that there is a significant difference at $1.5 \mathrm{mM}(* * * p$ $<0.001$ ), on the 4th and 7th days. On the 1st day, there was also a significant difference in microtissue diameters including $1.5 \mathrm{mM}$ YIGSR $(* * p<0.05)$.

As a result of the diameter analysis, increases in SFM sizes were observed at $0 \mathrm{mM}$ and $1.5 \mathrm{mM}$ peptide concentrations (Fig. 4). However, SFMs diameters were decreased in the $3 \mathrm{mM}$ YIGSR group. The most effective amount of used peptide concentrations was found as $1.5 \mathrm{mM}$. Because the $1.5 \mathrm{mM}$ YIGSR was statistically significant to increase in microtissue sizes. The viability of SFMs was performed on microtissues which contained $0 \mathrm{mM}, 1.5 \mathrm{mM}$ and $3 \mathrm{mM}$ peptide concentrations. The fluorescent microscopy images showing the live and dead cells for experimental groups of YIGSR concentrations at day 7 were shown in Fig. 5. A, B, and C, respectively.
Fig. 5 also showed that the merge of red and green images of SFMs. Red and green images were taken singly for each SFMs and then these images merged using Image J. The visual comparisons of Fig. 5. A, B, and $\mathrm{C}$ show that varying concentrations of YIGSR have noticeable effects on endothelial cell viability. Pixel density analysis of each fluorescent image was performed to quantify these visual comparisons. Mean fluorescence pixel intensity values of $0 \mathrm{mM}, 1.5 \mathrm{mM}$ and $3 \mathrm{mM}$ YIGSR microtissues were determined as shown Fig. 6.

The green and red color intensity of the $0 \mathrm{mM}$ YIGSR (control group) was accepted as $100 \%$ and this ratio was used for other peptide group comparisons. Among the used concentrations, $1.5 \mathrm{mM}$ has a higher green color density. According to pixel intensity analysis, the amount of $1.5 \mathrm{mM}$ YIGSR green color intensity was $23.12 \%$ higher than the green color intensity of the control group. The excess of green color has indicated that $1.5 \mathrm{mM}$ YIGSR group enhanced cell
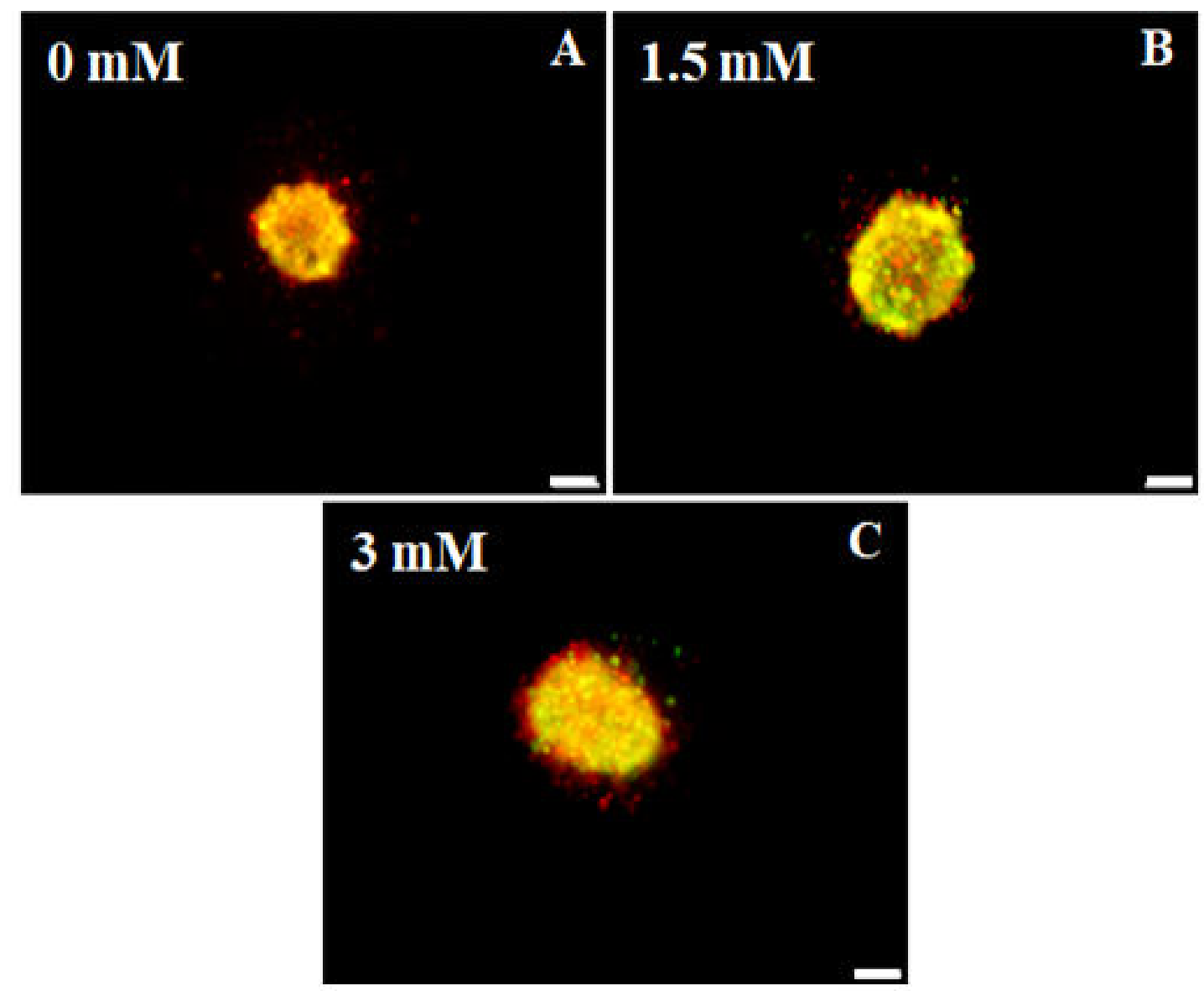

Fig. 5. Viability Assay (A) at $0 \mathrm{mM}$ YIGSR concentration, (B) at $1.5 \mathrm{mM}$ YIGSR concentration, and (C) at $3 \mathrm{mM}$ YIGSR concentration. The scale bar represents $100 \mu \mathrm{m}$. 


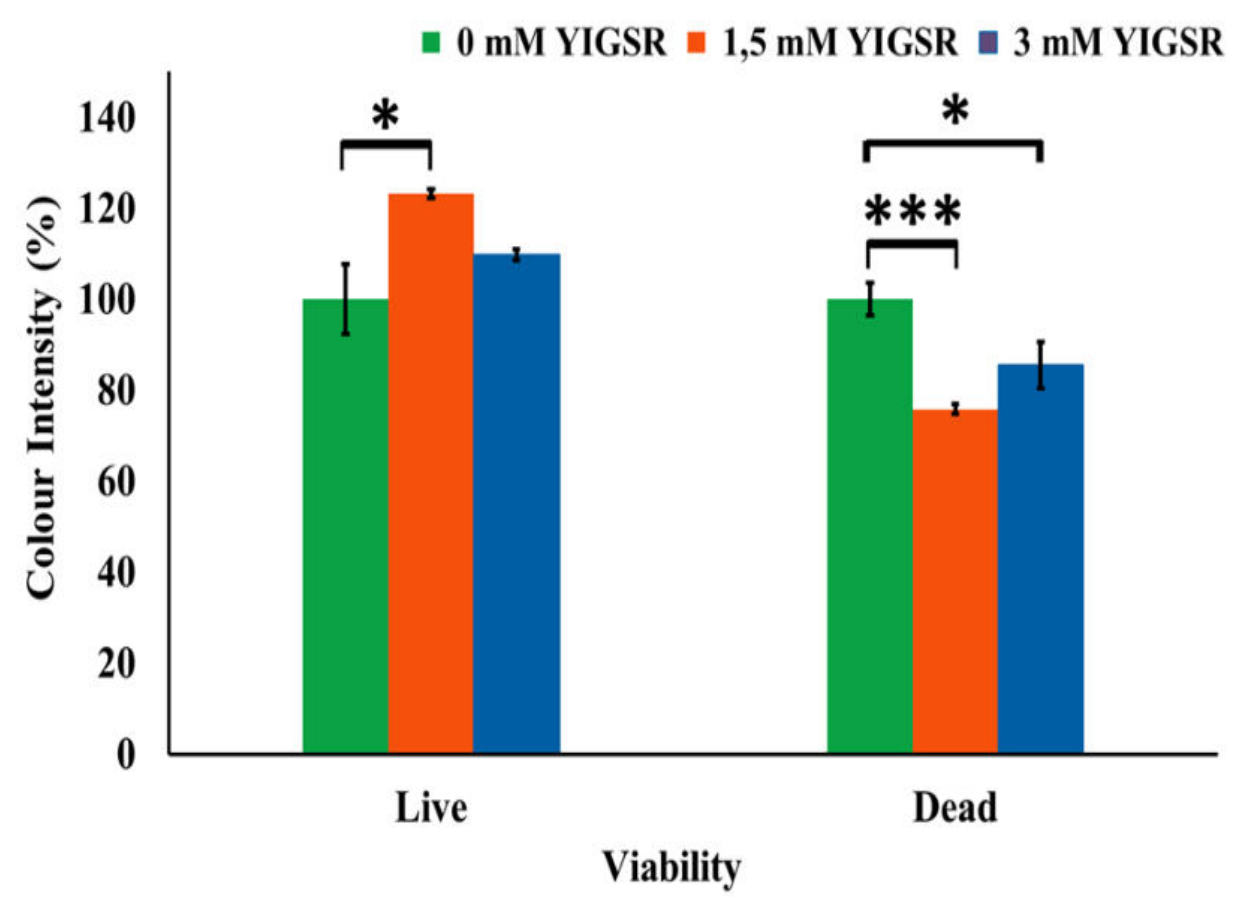

Fig. 6. Effects of $1.5 \mathrm{mM}$ YIGSR and $3 \mathrm{mM}$ YIGSR concentrations on SFMs viability.

viability. In addition, it is seen that the $1.5 \mathrm{mM}$ YIGSR group has a significantly low red color intensity compared to untreated microtissues. $3 \mathrm{mM}$ YIGSR increased the viability rate by $9.77 \%$ compared to the control group. It was observed that the microtissues with $3 \mathrm{mM}$ YIGSR had approximately $14.5 \%$ less red color intensity than the $0 \mathrm{mM}$ group. Both the decrease in red color and the increase in green color indicated that the use of YIGSR enhances the cellular vitality of HUVEC SFMs. Although $3 \mathrm{mM}$ contributed to viability, it caused a decrease in microtissue diameters. When all the results of used concentrations have been evaluated, it has been determined that the most effective YIGSR concentration was $1.5 \mathrm{mM}$. This peptide concentration contributed to viability significantly and caused an increase in SFM diameter.

\section{DISCUSSION}

Biomaterials regulate cellular response and induce migration, differentiation, and proliferation through increased cell-matrix and cell-surface interactions with specific molecules. Surface coating with functional parts of major extracellular matrix proteins such as laminin, collagen and fibronectin can increase cell proliferation, migration, and intercellular communica- tion [29]. Therefore, the use of bioactive peptides for enhanced tissue regeneration has recently taken an essential trend in tissue engineering studies [3, 24, 30, 31]. For cell proliferation, attachment and spreading, ECM mimicking bioactive peptides are important for tissue engineered constructs. One of the ECM proteins is laminin which affects cell attachment and spreading $[3,30]$. The reason is that cells with high surface adhesion and spreading rate are more prone to forming advanced tissues [32-35].

YIGSR is a pentapeptide, a laminin-derived peptide, is found in the $\beta 1$ chain of laminin protein. It has a key role in cell metabolism. Ali et al. [3] and Jun and West [22] indicated that YIGSR has important effects in endothelial cell proliferation, cell-to-cell interactions, adhesion, production of the extracellular matrix, and migration. Although YIGSR is a known peptide, the mechanisms of YIGSR have not been clearly enlightened, yet. Actually, YIGSR may interact with ECM proteins such as integrin and laminin which is mostly expressed in endothelial cells. Those molecules binds cells onto ECM so they can enhance cell viability and proliferation through cell receptor and ligand interaction [36, 37]. The interactions of YIGSR and integrin promote ECM connection which is critically important for HUVEC microenvironments [38]. Moreover, the immobilization of YIGSR on ECM can 
strikingly enhance HUVEC proliferations and cell movements [39]. Expression level of this receptor is associated with cell proliferation and migration. Correspondingly, Jun and West [22] showed that lamininderived YIGSR peptide increased the endothelial cell proliferation and ECM production.

The study examined that $1.5 \mathrm{mM}$ and $3 \mathrm{mM}$ YIGSR peptide concentrations enhanced the proliferation potency of HUVECs SFMs. SFMs with $1.5 \mathrm{mM}$, and $3 \mathrm{mM}$ YIGSR were used to understand the effects of the YIGSR peptide on the diameter differences of SFMs. Each experimental group was checked on the 1 st, 4th, and 7th days. All SFMs were created from the first day. It was clearly seen that the diameters of 1.5 $\mathrm{mM}$ and $3 \mathrm{mM}$ YIGSR increased at day 1 significantly, but then there was decrease in diameter of SFMs in $3 \mathrm{mM}$ YIGSR group. The diameter of the control group also decreased. At the end of 7th day, less efficacy was seen in $3 \mathrm{mM}$ YIGSR peptide concentration compared with $1.5 \mathrm{mM}$ peptide concentration. Studies of Martin et al. [26], Karaman and Yarali [27], and Yarali et al. [28] demonstrated that formation of SFMs develops depending on the diameter enlargement of SFMs. In light of that information, we concluded that both of YIGSR peptide concentrations provide enlargement of HUVEC SFMs and contributed to developing SFMs formation until the end of the 4th day. However, $3 \mathrm{mM}$ YIGSR peptide did not show spread of SFMs. We predicted that $3 \mathrm{mM}$ YIGSR peptide may have accumulated among SFMs because Iwamoto et al. [40] demonstrated that YIGSR may block binding proteins on cell membranes.

Andukuri et al. [41] indicated that YIGSR increased attachment, proliferation and also viability of HUVECs. YIGSR is a peptide that supports endothelial tissue formation. A similar study was reported that YIGSR promotes the activity of cellular metabolism and contributes to HUVECs viability [42]. Ovadia et al. [43] proved that $2 \mathrm{mM}$ CGKGYIGSR peptide combination in 3D hydrogel promotes induced pluripotent stem cell (iPSC) viability. The increase in SFM viability with the use of YIGSR peptide may also be associated with rising cellular metabolic activity. The vascularization process, which is a dynamic event, is very important for the sustainability of cellular vitality for vascular tissue formation [5]. Our study also showed that both $1.5 \mathrm{mM}$ YIGSR and $3 \mathrm{mM}$ YIGSR groups increased the viability of cells. End of the 7th day, $1.5 \mathrm{mM}$ YIGSR and $3 \mathrm{mM}$ YIGSR had more viability than the control group. Particularly, $1.5 \mathrm{mM}$ YIGSR peptide showed a significant augmentation in SFMs viability [44]. According to the results, we predicted that the YIGSR peptide enhances the survival of SFMs.

In this study, we examined the effects of the laminin-derived YIGSR peptide on HUVECs SFMs. The effects of $1.5 \mathrm{mM}$ YIGSR and $3 \mathrm{mM}$ YIGSR were determined in terms of diameter and viability analysis on HUVEC SFMs. As a conclusion, 1.5 mM YIGSR peptide was the most effective concentration compared with $3 \mathrm{mM}$ YIGSR group and control group without YIGSR.

\section{CONCLUSION}

Briefly, this study described the effect of laminin derived YIGSR peptide concentration in vitro development of HUVEC SFMs. YIGSR concentration contributed to cellular metabolism and proliferation of SFMs. Additionally, results confirmed that formation and viability of SFMs could be supported by YIGSR. Moreover, this study aimed to clarify the optimum YIGSR concentration on developing SFMs. Consequently, successful development of SFMs was observed in the $1.5 \mathrm{mM}$ YIGSR group. The results observed that SFM formation and viability relates with YIGSR concentration. We estimated that $1.5 \mathrm{mM}$ YIGSR concentration may promise to increase vascularization since it contributed to proliferation and viability of SFMs, which is the first step of vascularization. In the prevascularization of the HUVECs SFMs, $1.5 \mathrm{mM}$ YIGSR can be used to mimic the native ECM protein structures for fabrication of tissue-engineered constructs.

\section{Authors' Contribution}

Study Conception: ZBYÇ, AÖ, OK; Study Design: ZBYÇ, OK; Supervision: ZBYÇ, OK; Funding: OK; Materials: OK; Data Collection and/or Processing: ZBYÇ, AÖ; Statistical Analysis and/or Data Interpretation: ZBYÇ, AÖ; Literature Review: ZBYÇ, AÖ; Manuscript Preparation: ZBYÇ, AÖ, OK and Critical Review: ZBYÇ, AÖ, OK.

\section{Conflict of interest}


The authors disclosed no conflict of interest during the preparation or publication of this manuscript.

\section{Financing}

The authors disclosed that they did not receive any grant during conduction or writing of this study.

\section{REFERENCES}

1. Atala A, Bauer SB, Soker S, Yoo JJ, Retik AB. Tissue-engineered autologous bladders for patients needing cystoplasty. Lancet 2006;367:1241-6.

2. Chen Y, Ma M, Teng Y, Cao H, Yang Y, Wang Y, et al. Efficient manufacturing of tissue engineered cartilage in vitro by a multiplexed 3D cultured method. J Mat Chem B 2020;8:2082-95.

3. Ali S, Saik JE, Gould DJ, Dickinson ME, West JL. Immobilization of cell-adhesive laminin peptides in degradable PEGDA hydrogels influences endothelial cell tubulogenesis. BioRes Open Access 2013;2:241-9.

4. Rouwkema J, Khademhosseini A. Vascularization and angiogenesis in tissue engineering: beyond creating static networks. Trends Biotechnol 2016;34:733-45.

5. Naito H, Iba T, Takakura N. Mechanisms of new blood-vessel formation and proliferative heterogeneity of endothelial cells. Inter Immunol 2020;32:295-305.

6. Park HJ, Zhang Y, Georgescu SP, Johnson KL, Kong D, Galper JB. Human umbilical vein endothelial cells and human dermal microvascular endothelial cells offer new insights into the relationship between lipid metabolism and angiogenesis. Stem Cell Rev 2006;2:93-101.

7. Kale S, Hanai JI, Chan B, Karihaloo A, Grotendorst G, Cantley LG, et al. Microarray analysis of in vitro pericyte differentiation reveals an angiogenic program of gene expression. FASEB J 2005;19:270-1.

8. Laranjeira M, Fernandes M, Monteiro F. Reciprocal induction of human dermal microvascular endothelial cells and human mesenchymal stem cells: time-dependent profile in a co-culture system. Cell Prolif 2012;45:320-34.

9. Duval K, Grover H, Han L-H, Mou Y, Pegoraro AF, Fredberg $\mathrm{J}$, et al. Modeling physiological events in $2 \mathrm{D}$ vs. $3 \mathrm{D}$ cell culture. Physiology (Bethesta) 2017;32:266-77.

10. Fang X, Sittadjody S, Gyabaah K, Opara EC, Balaji KC. Novel 3D co-culture model for epithelial-stromal cells interaction in prostate cancer. PloS One 2013;8:e75187.

11. Baker BM, Chen CS. Deconstructing the third dimensionhow 3D culture microenvironments alter cellular cues. J Cell Sci 2012;125:3015-24.

12. Antoni D, Burckel H, Josset E, Noel G. Three-dimensional cell culture: a breakthrough in vivo. Int J Mol Sci 2015;16:551727.

13. Zhang W, Zhuang A, Gu P, Zhou H, Fan X. A review of the three-dimensional cell culture technique: approaches, advantages and applications. Curr Stem Cell Res Ther 2016;11:370-80.

14. Iorio V, Troughton LD, Hamill KJ. Laminins: roles and utility in wound repair. Adv Wound Care (New Rochelle) 2015;4:25063.

15. Walker C, Mojares E, Del Río Hernández A. Role of extracellular matrix in development and cancer progression. Int J Mol Sci 2018;19:3028.

16. Yap L, Tay HG, Nguyen MT, Tjin MS, Tryggvason K. Laminins in cellular differentiation. Trends Cell Biol 2019;29:987-1000.

17. Itoh S, Matsuda A, Kobayashi H, Ichinose S, Shinomiya K, Tanaka J. Effects of a laminin peptide (YIGSR) immobilized on

crab-tendon chitosan tubes on nerve regeneration. J Biomed Mat Res B Appl Biomater 2005;73:375-82.

18. Kikkawa Y, Hozumi K, Katagiri F, Nomizu M, Kleinman HK, Koblinski JE. Laminin-111-derived peptides and cancer. Cell Adh Migr 2013;7:150-256.

19. Kim Y-Y, Li H, Song YS, Jeong H-S, Yun H-Y, Baek KJ, et al. Laminin peptide YIGSR enhances epidermal development of skin equivalents. J Tissue Viability. 2018;27:117-21.

20. Motta CM, Endres KJ, Wesdemiotis C, Willits RK, Becker ML. Enhancing Schwann cell migration using concentration gradients of laminin-derived peptides. Biomaterials 2019;218:119335.

21. Su J, Satchell SC, Wertheim JA, Shah RN. Poly (ethylene glycol)-crosslinked gelatin hydrogel substrates with conjugated bioactive peptides influence endothelial cell behavior. Biomaterials 2019;201:99-112.

22. Jun HW, West J. Development of a YIGSR-peptide-modified polyurethaneurea to enhance endothelialization. J Biomater Sci Polym Ed 2004;15:73-94.

23. Taite LJ, Yang P, Jun HW, West JL. Nitric oxide-releasing polyurethane-PEG copolymer containing the YIGSR peptide promotes endothelialization with decreased platelet adhesion. J Biomed Mater Res B Appl Biomater 2008;84:108-16.

24. Fittkau MH, Zilla P, Bezuidenhout D, Lutolf MP, Human P, Hubbell JA, et al. The selective modulation of endothelial cell mobility on RGD peptide containing surfaces by YIGSR peptides. Biomaterials 2005;26:167-74.

25. Peng G, Yao D, Niu Y, Liu H, Fan Y. Surface modification of multiple bioactive peptides to improve endothelialization of vascular grafts. Macromol Biosci 2019;19:1800368.

26. Martin F, Lehmann M, Schläger P, Sack U, Anderer U. Differentiation capacity of chondrocytes in microtissues depends on TGF-ß subtype. J Biochip Tissue chip 2012;S2:002.

27. Karaman O, Yaralı ZB. Determination of minimum serum concentration to develop scaffold free micro-tissue. Eur Res J 2018;4:145-51

28. Yaralı ZB, Onak G, Karaman O. Effect of integrin binding peptide on vascularization of scaffold-free microtissue spheroids. Tissue Eng Regen Med 2020;17:595-605.

29. Shin H, Jo S, Mikos AG. Biomimetic materials for tissue engineering. Biomaterials 2003;24:4353-64.

30. Patel R, Santhosh M, Dash JK, Karpoormath R, Jha A, Kwak $\mathrm{J}$, et al. Ile-Lys-Val-ala-Val (IKVAV) peptide for neuronal tissue engineering. Polym Adv Technol 2019;30:4-12.

31. Righi M, Puleo GL, Tonazzini I, Giudetti G, Cecchini M, 
Micera S. Peptide-based coatings for flexible implantable neural interfaces. Sci Rep 2018;8:1-14.

32. Da Silva LP, Reis RL, Correlo VM, Marques AP. Hydrogelbased strategies to advance therapies for chronic skin wounds. Annu Rev Biomed Eng 2019;21:145-69.

33. Gumbiner BM. Cell adhesion: the molecular basis of tissue architecture and morphogenesis. Cell 1996;84:345-57.

34. Saleh NT, Sohi AN, Esmaeili E, Karami S, Soleimanifar F, Nasoohi N. Immobilized laminin-derived peptide can enhance expression of stemness markers in mesenchymal stem cells. Biotechnol Bioprocess Eng 2019;24:876-84.

35. Zheng W, Liu M, Qi H, Wen C, Zhang C, Mi J, et al. Musselinspired triblock functional protein coating with endothelial cell selectivity for endothelialization. J Colloid Interface Sci 2020;576:68-78.

36. Massia SP, Rao SS, Hubbell JA. Covalently immobilized laminin peptide Tyr-Ile-Gly-Ser-Arg (YIGSR) supports cell spreading and co-localization of the 67-kilodalton laminin receptor with alpha-actinin and vinculin. J Biol Chem 1993:268:80539.

37. Jain R, Roy S. Controlling neuronal cell growth through composite laminin supramolecular hydrogels. ACS Biomater Sci Eng 2020:6:2832-46.

38. Oliveira H, Médina C, Stachowicz ML, dos Santos BP, Chagot L, Dusserre N, et al. Extracellular matrix (ECM)-derived bioinks designed to foster vasculogenesis and neurite outgrowth:
Characterization and bioprinting. Bioprinting 2021:22:e0134.

39. Cui Y, Yang Y, Qiu D. Design of selective cell migration biomaterials and their applications for tissue regeneration. J Mater Sci 2021:56:4080-96.

40. Iwamoto Y, Nomizu M, Yamada Y, Ito Y, Tanaka K, Sugioka Y. Inhibition of angiogenesis, tumour growth and experimental metastasis of human fibrosarcoma cells HT1080 by a multimeric form of the laminin sequence Tyr-Ile-Gly-Ser-Arg (YIGSR). Br J Cancer 1996;73:589-95.

41. Andukuri A, Minor WP, Kushwaha M, Anderson JM, Jun HW. Effect of endothelium mimicking self-assembled nanomatrices on cell adhesion and spreading of human endothelial cells and smooth muscle cells. Nanomedicine 2010;6:289-97.

42. Noel S, Hachem A, Merhi Y, De Crescenzo G. Development of a polyester coating combining antithrombogenic and cell adhesive properties: influence of sequence and surface density of adhesion peptides. Biomacromolecules 2015;16:1682-94.

43. Ovadia EM, Colby DW, Kloxin AM. Designing well-defined photopolymerized synthetic matrices for three-dimensional culture and differentiation of induced pluripotent stem cells. Biomater Sci 2018;6:1358-70.

44. Lim D-J, Andukuri A, Vines JB, Rahman SM, Hwang PT, Kim J, et al. Enhanced MIN-6 beta cell survival and function on a nitric oxide-releasing peptide amphiphile nanomatrix. Int $\mathbf{J}$ Nanomedicine 2014;9(Suppl 1):13-21. 